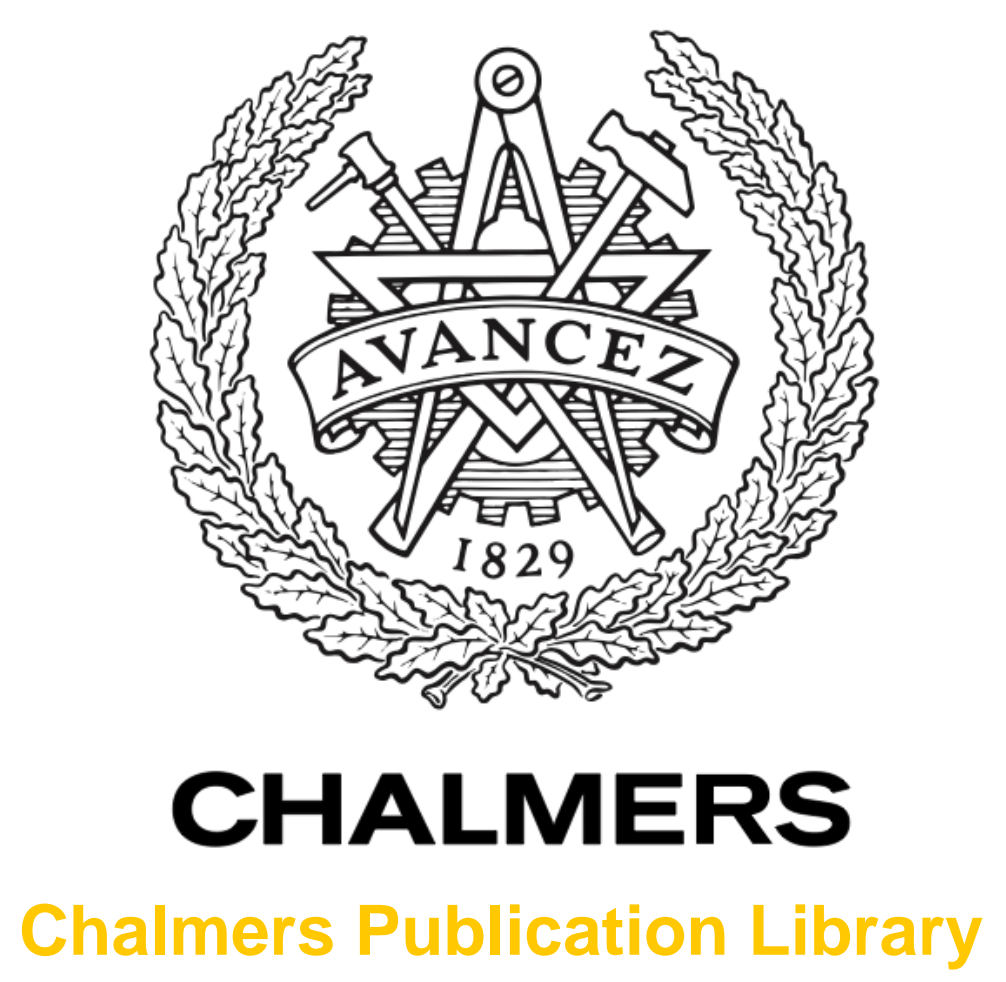

Estimating the Solids Circulation Rate in a 100-kW Chemical Looping Combustor

This document has been downloaded from Chalmers Publication Library (CPL). It is the author's version of a work that was accepted for publication in:

Chemical Engineering Science (ISSN: 0009-2509)

Citation for the published paper:

Linderholm, C. ; Schmitz, M. ; Lyngfelt, A. (2017) "Estimating the Solids Circulation Rate in a 100-kW Chemical Looping Combustor". Chemical Engineering Science, vol. 2017 pp. 351 â359.

Downloaded from: http://publications.lib.chalmers.se/publication/250693

Notice: Changes introduced as a result of publishing processes such as copy-editing and formatting may not be reflected in this document. For a definitive version of this work, please refer to the published source. Please note that access to the published version might require a subscription.

Chalmers Publication Library (CPL) offers the possibility of retrieving research publications produced at Chalmers University of Technology. It covers all types of publications: articles, dissertations, licentiate theses, masters theses, conference papers, reports etc. Since 2006 it is the official tool for Chalmers official publication statistics. To ensure that Chalmers research results are disseminated as widely as possible, an Open Access Policy has been adopted.

The CPL service is administrated and maintained by Chalmers Library. 


\section{AUTHOR VERSION}

Estimating the Solids Circulation Rate in a 100-kW Chemical Looping Combustor

Carl LINDERHOLM, Matthias SCHMITZ, Anders LYNGFELT

Work published in Chemical Engineering Science 


\title{
Estimating the Solids Circulation Rate in a 100-kW Chemical Looping Combustor
}

\author{
Carl Linderholm, Matthias Schmitz, and Anders Lyngfelt
}

\begin{abstract}
Chemical looping combustion (CLC) is a technology of $\mathrm{CO}_{2}$ capture that can drastically reduce its cost. The solids circulation inside a $100-\mathrm{kW}$ chemical looping combustor was investigated using a novel oxygen carrier called Sinaus by adding fuel batches to the fuel reactor. The decline and subsequent rise of oxygen concentration in the air reactor after each addition was used to determine the residence time of solids in the fuel reactor and adjacent vessels. The obtained residence time, in combination with the solids inventory, determined the solids circulation for a particular batch experiment. After performing a number of such experiments, the above circulation was correlated with other experimental data, revealing a good correlation between the solids flow at the top of the air reactor riser and the actual circulation obtained using batch tests. The relationship between global circulation, $\dot{m}$, and the mass flow in the air reactor riser, $\dot{m}_{r i s e r}$, was found to be linear within the investigated interval, being described as $\dot{m}=6.6+0.057 \dot{m}_{\text {riser }}$. Although this correlation was valid only for the investigated reactor system, the approach used to obtain the solids circulation could be used to derive a similar correlation for any dual fluidized bed system.
\end{abstract}




\begin{tabular}{|c|c|c|}
\hline Abbreviations and symbols & Unit(s) & Explanation \\
\hline $\mathbf{A R}$ & & Air reactor \\
\hline CCS & & Carbon capture and storage \\
\hline CFB & & Circulating fluidized bed \\
\hline CLC & & Chemical-looping combustion \\
\hline CR & & Circulation riser \\
\hline $\mathbf{C S}$ & & Carbon stripper \\
\hline CSTR & & Continuous stirred tank reactor \\
\hline FR & & Fuel reactor \\
\hline FR+ & & $\begin{array}{l}\text { Fuel reactor and adjacent reactor vessels, including } \\
\text { CR, CS LS2, LS3, LS4 }\end{array}$ \\
\hline $\mathbf{L S}$ & & Loop seal \\
\hline PFR & & Plug flow reactor \\
\hline RTD & & Residence time distribution \\
\hline$A, A_{c}$ & & Cross sectional area \\
\hline d50 & $\mu \mathrm{m}$ & $\begin{array}{l}\text { The mass-median diameter; one way of expressing } \\
\text { the average particle size by mass }\end{array}$ \\
\hline$G_{s}$ & $\mathrm{~kg} /\left(\mathrm{s}, \mathrm{m}^{2}\right)$ & Solids flux \\
\hline$m_{F R+}$ & $\mathrm{kg}$ & Solids inventory in FR+ \\
\hline$\dot{m}$ & $\mathrm{~kg} / \mathrm{min}$ & Circulation, or global solids flow \\
\hline$\dot{m}_{\text {riser }}$ & $\mathrm{kg} / \mathrm{min}$ & Solids circulation in air reactor riser \\
\hline$N$ & - & Number of CSTRs \\
\hline$\left(O_{2}\right)_{A R}(t)$ & $\%$ & Concentration of $\mathrm{O}_{2}$ in $\mathrm{AR}$ exit gas at time $\mathrm{t}$ \\
\hline$p$ & $\mathrm{~Pa}$ & pressure \\
\hline$r^{2}$ & - & Coefficient of determination \\
\hline$T_{F R,} T_{A R}$ & ${ }^{\circ} \mathrm{C}$ & Temperature in FR/AR \\
\hline$u_{0}$ & $\mathrm{~m} / \mathrm{s}$ & Superficial velocity \\
\hline$u_{t}$ & $\mathrm{~m} / \mathrm{s}$ & Terminal velocity \\
\hline Papparent & $\mathrm{kg} / \mathrm{m}^{3}$ & Apparent density of oxygen carrier material \\
\hline$\rho_{\text {exit }}$ & $\mathrm{kg} / \mathrm{m}^{3}$ & Solids loading at the exit of the air reactor riser \\
\hline$\tau$ & $\mathrm{s}$ & Residence time \\
\hline$\tau_{i}$ & $\mathrm{~s}$ & Residence time in bed i \\
\hline
\end{tabular}




\section{Introduction}

Carbon capture and storage is an economically attractive method of avoiding $\mathrm{CO}_{2}$ emission into the atmosphere, with negative emissions being possible if biomass is used as fuel. Chemical looping combustion (CLC) is a technology that can drastically reduce the cost of $\mathrm{CO}_{2}$ capture, featuring systems based on interconnected fluidized beds comprising metal oxide particles as oxygen carriers. These particles transport oxygen from combustion air to fuel, making $\mathrm{CO}_{2}$ capture an inherent feature of the CLC process. Control of the chemical looping process requires knowing the circulation of solids between two principal interconnected beds, i.e., the air (AR) and fuel (FR) reactors.

Although Ishida et al. were the first to recognize the potential of CLC as a $\mathrm{CO}_{2}$ capture technology potentially exhibiting no energy penalty [1], the concept of chemical looping for the purpose of $\mathrm{CO}_{2}$ production was patented already in 1954 by Lewis and Gilliland [2]. The first CLC pilot based on interconnected fluidized beds was constructed and operated in 2003. Today, chemical looping operations described in literature amount to at least $9000 \mathrm{~h}$ in 34 pilots [3]. Most of the operational experience related to chemical looping combustors was obtained using gaseous fuels and manufactured oxygen carriers, with oxygen carrier development reviewed by Lyngfelt [4] and Wang et al. [5]. In the case of chemical looping operation using solid fuels, low-cost materials such as ores or waste materials are often used. The reason for the increased attention enjoyed by low-cost materials is that (i) solid fuels normally contain significant quantities of ash, which is expected to lower the oxygen carrier lifetime, and (ii) hydrocarbons contained in typical gaseous fuels such as natural gas require more reactive oxygen carrier materials than the gas released from solid fuels, which contains larger amounts of reactive $\mathrm{H}_{2}$ and $\mathrm{CO}$. Several research groups have reported the design and operation of 0.5-50-kW chemical looping combustors [6-14], and a 1-MW pilot has been built and autothermally operated using ilmenite (a natural mineral widely used as an oxygen carrier in CLC applications) as an oxygen carrier $[15,16]$. More than $3000 \mathrm{~h}$ of operation using solid fuels has been reported in total, with $1570 \mathrm{~h}$ corresponding to low-cost oxygen carriers Low-cost materials include iron ores and iron-based waste materials, ilmenite, and manganese ores. Using ilmenite as oxygen carrier and bituminous coal as fuel, the expected lifetime of oxygen carrier particles was investigated in a $100 \mathrm{~kW}$ reactor system - described below - and found to be 700-800 h [17]. Compared to ilmenite, manganese ore has shown higher reactivity with syngas. This was demonstrated in a study by Sundqvist et al. [18] who investigated 11 manganese ores in a laboratory fluidized bed, and estimated the rate constant for the 8 most reactive ores to be 3-6 times higher as compared to ilmenite.

Moreover, the presence of manganese ore has also been shown to give a higher rate of steam gasification of char in both lab tests [19] and a continuous unit [20].

In order to find out how particles will behave over time in full-scale applications, evaluation in larger, continuous units is a vital step. The expected lifetime of the oxygen-carrying particles may be a very important parameter when it comes to process up-scaling. Lyngfelt and Leckner [21] recently proposed a design of a $1000 \mathrm{MW}$ CLC system, which is very similar to a state-of-the-art CFB boiler. The authors find that the additional cost of the CLC-CFB system, relative to conventional state-of-the art $\mathrm{CFB}$ technology, is around $20 € /$ tonne $\mathrm{CO}_{2}$. In other words, the cost of $\mathrm{CO}_{2}$ capture is significantly lower as compared to other capture technologies.

Satisfactory circulation of solids is a fundamental prerequisite for the design and control of any chemical looping process, with insufficient circulation causing (a) a high temperature difference between the AR and FR, i.e., low fuel reactor temperature, and (b) an insufficient amount of oxygen supplied to fuel. Although the circulation of solids in fluidized beds is difficult to measure due to high temperatures and mechanical wear caused by the moving bed material, a large number of methods have been proposed and investigated. Bhusarapu et al. [22] listed six groups of such measurements, 
namely optical, radioactive, electrical, tracer, acoustical, heat/mass transfer, and mechanical. Most of these methods have been developed for cold conditions and are excellent for predicting the flow of solids in cold-flow units only, being unsuited for high-temperature systems. Furthermore, a large number of these methods are invasive, making them hard to implement in the case of continuous operation. Thus, an ideal method should allow direct on-line measurements of the solids circulation.

In CLC, the circulation of solids supplies oxygen and heat to the fuel in the fuel reactor. Using a 1.5$\mathrm{kW}$ continuous chemical looping combustor, Abad et al. [23] developed a valve (situated between the cyclone and the fuel reactor) for diverting the flow of solids, enabling circulation measurement and control. However, mechanical valves are normally impractical or very difficult to manage in larger units. Dietrich et al. [24] investigated four approaches to achieve the circulation of solids, with two of them supposedly being suitable for hot conditions. However, both of these methods rely on deactivating fluidization in a loop seal for a certain period of time, which might lead to agglomeration, sintering, and operation discontinuation for some oxygen carrier materials. Using a Ni-based oxygen carrier and natural gas as a fuel in a 10-kW CLC unit, Linderholm et al. [25] developed a method for measuring the solids circulation based on the temperature difference between the AR and FR, which requires autothermal operation and full or close-to-full fuel conversion, thus being unsuitable for operation employing solid fuel. Using a 150-kW CLC unit for gaseous fuels, Kolbitsch [26] showed that the mass flow of solids through a loop seal can be estimated from the corresponding pressure drop, i.e., the pressure difference between a point at a specific height on the incoming side of the seal and that at the same height on the exit side. This loss of pressure results from frictional forces of the two-phase flow (gas-solids) in the loop seal, increasing with increasing circulation. Studying two loop seals, Kolbitsch observed a linear correlation between the mass flow of solids and the abovementioned pressure drop. At identical circulation, different pressure loss responses were observed for the two studied loop seals, which was attributed to "slight differences in fluidization".

The present study mainly focuses on analyzing the residence time distribution (RTD) of oxygen carrier materials in the FR section of the 100-kW reactor system. With the help of RTD, residence time, and knowledge of the solids inventory, the circulation of solids was determined for a specific operational setting, i.e., for a specific batch experiment. After performing a number of batch experiments, the circulation of solids was correlated with other experimental data, e.g., pressure drops measured in the AR riser or pressure losses in a loop seal, as explained above, with the strong correlation observed providing a tool for real-time estimation of the global solids circulation in the 100-kW unit, which is very useful during operation. Although such a correlation was valid only for the investigated reactor system, the general applicability of this approach could be used to determine the circulation of solids in any other dual fluidized bed system.

Using ilmenite as an oxygen carrier, Markström et al. described how the solids circulation, $\dot{m}$, can be estimated from the pressure drop and gas superficial velocity [27]. The mass flow in the riser, $\dot{m}_{\text {riser }}$, was defined as:

$$
\dot{m}_{\text {riser }}=\frac{A_{c}}{g} \frac{\Delta p_{\text {riser }}}{\Delta h}\left(u_{0}-u_{t}\right)
$$

where $A_{c}$ is the cross-sectional riser area, $g$ is the gravitational acceleration, $\Delta p_{\text {riser }}$ is the pressure drop between two pressure taps at the top of the riser, $\Delta h$ is the distance between these pressure taps, $u_{0}$ is the superficial velocity in the riser, and $u_{t}$ is the terminal velocity of an average-size particle in a specific physical environment. Markström et al. modeled the FR and adjacent vessels as a number of sequentially connected CSTRs followed by a plug-flow reactor. The solids circulation during batch 
experiments was determined by analyzing the RTD of solids and was subsequently correlated to $\dot{m}_{r i s e r}$, with $\dot{m}$ found to be directly proportional to $\dot{m}_{\text {riser }}$ :

$$
\dot{m}=0.081 \dot{m}_{\text {riser }} \text {. }
$$

The physical interpretation of this relationship implies that $91.9 \%$ of the material moving up along the riser falls back down, with only $8.1 \%$ continuing further to LS1 and the fuel reactor. The present work adopted a modeling approach similar to that developed by Markström et al. to determine the solids circulation during batch experiments. In contrast to the work of the above researchers, we (i) used a different oxygen carrier, (ii) collected more data (24 tests instead of one), allowing a more rigorous statistical analysis, and (iii) correlated the circulation determined in batch experiments with both the internal mass flow in the riser and the pressure drop inside two loop seals.

\section{Experimental}

\section{Chalmers 100-kW CLC unit for solid fuels}

The Chalmers $100 \mathrm{~kW}$ chemical-looping combustor was designed to be an operationally flexible system. This resulted in a rather complex system of interconnected fluidized beds, including two CFBs, i.e. the air reactor (AR) and the fuel reactor (FR), as well as a carbon stripper. The fuel reactor is $5 \mathrm{~m}$ high with an inner diameter of $0.154 \mathrm{~m}$, and the air reactor is $4 \mathrm{~m}$ high with a riser having the same size as the fuel reactor, and an expanded bottom section with a diameter of $0.4 \mathrm{~m}$. The fluidization velocity in the air reactor is the primary controller for global circulation. The circulation riser (CR) was designed to return oxygen-carrier particles to the AR while keeping the total height of the system down. The fluidization velocity in the CR can hence also influence the circulation rate of solids. The fuel reactor (FR) is a circulating fluidized bed, the particles are separated in cyclone 2 (CY2) and recycled via the loop seal 2 (LS2). Fuel is added at the outlet of LS2, hence in immediate proximity to the fuel reactor, but into a space where particle loading is low. The carbon stripper has four chambers separated by under and over weirs and then a final overflow leading to LS4. Ideally, all fuel particles will be entrained with the gas and be separated from the gas in CY2. The $100 \mathrm{~kW}$ reactor system has been described in more detail in a study by Markström et al. [9], who determined its complete pressure profile. Pressure taps B and C (Figure 1) were used to measure the pressure losses in LS3 and LS4. Table 1 summarizes important design and operational data pertaining to the $100-\mathrm{kW}$ CLC unit.

Table 1. Important characteristics and operational data for the 100-kW chemical looping combustor.

Operating temperature $\left({ }^{\circ} \mathrm{C}\right)$

\begin{tabular}{ll}
\hline Total solids inventory $(\mathrm{kg})$ & $150-250$ \\
\hline Total height $(\mathrm{m})$ & 5 \\
\hline $\mathbf{u}_{0}$, AR riser $(\mathrm{m} / \mathrm{s})$ & $7-10$ \\
\hline $\mathbf{u}_{0}$, AR bottom section $(\mathrm{m} / \mathrm{s})$ & $1-1.5$ \\
\hline Fluidization gas & Air (in AR), steam \\
\hline Gas distribution & Wind boxes and bubble caps \\
\hline Construction material & 253 MA (corresponds to standards SS \\
& 2368 and UNS S30815) \\
\hline
\end{tabular}




\section{Oxygen carrier}

The oxygen carrier material used in this study, Sinaus, was a sintered manganese ore originally produced for the ferroalloy industry. This material, approximately $5-30 \mathrm{~cm}$ in size, was crushed and sieved by UVR-FIA in Freiberg, Germany. The poured bulk density of the Sinaus material was 2090 $\mathrm{kg} / \mathrm{m}^{3}$. The density of the material did not change as an effect of operation. It can further be noted that the density of used Sinaus material is very similar to used ilmenite oxygen carrier. Approximately $4 \%$ of the material used in operation was larger than $355 \mu \mathrm{m}$. The density of this larger material was $1500 \mathrm{~kg} / \mathrm{m}^{3}$. The material seemed to have undergone swelling, the mechanisms behind which will be explored in another study. The crushing strength of the material was obtained as the average of 30 measurements on particles of size 180-212 $\mu \mathrm{m}$. Table 2 summarizes some general properties of fresh and used material.

Table 2. Selected properties of fresh and used oxygen carriers.

\begin{tabular}{|lr|}
\hline Property & Value \\
\hline $\boldsymbol{\rho}_{\text {bulk, }}$, fresh $\left(\mathrm{kg} / \mathrm{m}^{\mathbf{3}}\right)$ & 2090 \\
\hline Crushing strength, fresh $(\boldsymbol{N})$ & 3.5 \\
\hline $\boldsymbol{d}_{50}$, fresh material $(\boldsymbol{\mu m})$ & 174 \\
\hline $\boldsymbol{d}_{50}$, used, AR & 229 \\
\hline $\boldsymbol{d}_{50}$, used, FR & 165 \\
\hline $\boldsymbol{u}_{\boldsymbol{t}}{ }^{*}(\mathrm{~m} / \mathbf{s})$ & 0.8 \\
\hline
\end{tabular}

*Terminal velocity in air at $1000{ }^{\circ} \mathrm{C}$ for fresh material.

Sinaus was used for $58 \mathrm{~h}$ of continuous operation in the Chalmers 100-kW unit, with fuel conversion and expected oxygen carrier lifetime determined for coal, wood char, petcoke [28], and wood pellets [29].

Figure 2 shows the particle size distribution of fresh and used oxygen carriers determined by drysieving $\sim 100 \mathrm{~g}$ of material, revealing a significant FR-AR difference in terms of particle size. The reason for this difference was related to the AR geometry, which makes it difficult for larger particles to be entrained from the bottom bed. The bottom section of the AR was $0.4 \mathrm{~m}$ in diameter, as compared to the value of $0.154 \mathrm{~m}$ for the riser section. This difference resulted in a seven-fold velocity increase in the riser compared to that in the bottom section, implying that larger particles tended to remain in the AR or at least had a significantly longer residence time than smaller particles. This behavior could be illustrated by considering the terminal velocity differences for particles of different sizes, i.e., for Sinaus particles in air at $1000{ }^{\circ} \mathrm{C}$, the terminal velocities equal 3.3 and $0.3 \mathrm{~m} / \mathrm{s}$ for 400 and $100-\mu \mathrm{m}$ particles. For comparison, the superficial velocity in the bottom section of the air reactor equaled $1-1.5 \mathrm{~m} / \mathrm{s}$ ( $c f$. Table 1). Thus, particles in the FR should better represent the circulating material than those in the AR.

Figure 3 shows optical microscopy images of Sinaus particles, revealing edge rounding as a clear effect of the mechanical wear experienced during operation, since fresh particles exhibited sharper edges than their used counterparts. No material agglomeration was observed during operation.

\section{Circulation of solids}

The flux of solids in the 100-kW CLC unit could not be measured directly. However, for a specific oxygen carrier and unit geometry, the circulation of solids is a function of the air velocity and the 
pressure drop in the riser. The following correlation provides a measure of the net flux of solids in the AR riser [30]:

$G_{s}=\rho_{e x i t}\left(u_{0}-u_{t}\right)=-\frac{1}{g} \frac{d p}{d h}\left(u_{0}-u_{t}\right)\left(\mathrm{kg} /\left(\mathrm{m}^{2} \mathrm{~s}\right)\right)$,

where $\rho_{\text {exit }}$ is the density of solids at the cyclone inlet. Although the direct determination of $\rho_{\text {exit }}$ is not possible, integration of $d p / d h$ over a large riser section allows the differential pressure drop between two pressure taps to be used as an indicator, providing the average holdup of solids at the top of the AR riser. This approach significantly overestimates the circulation of solids. $G_{s}$ multiplied by the cross-sectional area of the riser affords the particle mass flow, $\dot{m}_{\text {riser }}$, eq. (1).

In an ideal continuously stirred tank reactor (CSTR), the inlet flow is instantly mixed with the bulk reactor contents, with the outlet fluid being homogeneous at all times. For such a reactor, the RTD is given by

$E(t)=\frac{1}{\tau} e^{-t / \tau}$

where $t$ is time, and $\tau$ is the residence time. This expression can be generalized for $N$ CSTRs connected in series:

$E(t)=\frac{1}{(N-1) ! \tau_{i}}\left(\frac{t}{\tau_{i}}\right)^{N-1} e^{-t / \tau_{i}}$.

Here, $\tau$ is the residence time of a system of beds connected in series, and $\tau_{i}=\tau / N$ is the residence time of each CSTR. Notably, the residence time distribution approaches that of a plug-flow reactor (PFR) with increasing $N$.

Markström et al. [31] showed that the RTD of equal-size CSTRs can model the residence time of the bed material (i.e., char and oxygen carrier particles) in the FR and adjacent reactor vessels before it enters the AR. Since the fuel is fed in batches, output data are obtained from the oxygen concentration in the AR, where the oxygen carrier is oxidized and any remaining char is burnt. Hence, when the reduced bed material from the FR arrives to the AR, oxygen will be consumed for as long as reduced oxygen carrier and char keep entering. The result is that the decline and subsequent rise in oxygen concentration will have the same time dependence as the residence-time distribution in eq. (5). The $\mathrm{O}_{2}$ concentration profile in the AR can then be modelled as

$\left(O_{2}\right)_{A R}(t)=\left(O_{2}\right)_{A R}(t=0)-k t^{(N-1)} e^{-t /(\tau / N)}$

where $\left(O_{2}\right)_{A R}(t)$ is the concentration of oxygen in the AR exit gas at time $t$, and $k$ is a constant.

In the next section, we present the measured oxygen concentrations as functions of time along with least-square-optimized fits, allowing the residence time, $\tau$, to be derived. Finally, the average mass flow of solids, $\overline{\dot{m}}$, during a specific experiment can be calculated as

$\overline{\dot{m}}=m_{F R+} / \tau$,

where $m_{F R+}$ is the sum of inventories in FR, CR, CS, LS2, LS3, and LS4, with LS1 excluded due to the fuel being introduced downstream of it. 


\section{Results and discussion}

The batches were fed for 22-40 s using a fuel feeding screw, corresponding to the introduction of 200-300 g into the reactor system. Depending on the circulation of solids, 2-4 batch tests per hour could be performed. A bituminous coal from Colombia having a volatile content of $29 \%$ was used as a fuel (for details, refer to "Calenturitas coal" in [32]). The FR and AR temperatures equaled 920-980 and $930-1000{ }^{\circ} \mathrm{C}$, respectively.

The bed inventory of the $100-\mathrm{kW}$ unit was calculated using pressure drops. The bed masses in different reactor vessels are shown in Figure 4, varying between 175 and $225 \mathrm{~kg}$. The "FR+" bed mass used in the calculations below is the sum of FR, CR, CS, LS2, LS3, and LS4 inventories, varying from 99 to $155 \mathrm{~kg}$. The solids inventory in the FR, and thus also in the FR+ section, was largely dependent on the solids circulation: at high circulation, the FR bed level rose above the overflow exit, leading to pressure drops of up to $25 \mathrm{kPa}$. A constant solids inventory of $12 \mathrm{~kg}$ in LS3 was assumed, since the pressure tap LS3A ( $c f$. Figure 1) was clogged.

Figure 5 depicts measured residence time distributions along with fitting functions (eq. (6)) for four of the 24 batch tests performed in this study, which were chosen to represent typical responses of the oxygen concentration in the air reactor for different solids circulations. The legends show eq. (5) with output data (constants $\left(\mathrm{O}_{2}\right)_{A R}(t=0), k, N$ and $\tau$ ). $N$ and $\tau$ are given in Table 3 for all experiments. The start of each experiment ( $t=0$ min in Figure 5) was defined as the time when approximately half of the fuel batch had been fed into the fuel reactor, i.e., 10-20 s after the onset of fuel feeding. The time period used to model circulation in batch experiments was chosen by analyzing experimental data. The final part of each experiment, when the oxygen concentration increased to its initial value, was excluded due to the "dead volume tail" phenomenon caused by poor mixing in certain parts of the system, such as corners. This phenomenon causes a time delay (not represented in the model), which is expected to result in a smaller oxygen concentration slope during the last minutes of the experiment.

Table 3 summarizes the results of all 24 batch experiments performed in the 100-kW unit using Sinaus as an oxygen carrier. The mass flow in the AR riser, $\dot{m}_{\text {riser }}$, was calculated using (i) the pressure drop between the top pressure tap, AR8, and the closest pressure tap below AR8, i.e., AR7 (Figure 1), and (ii) the pressure drop between AR8 and the pressure tap below AR7, i.e., AR6. The distance between AR7 and AR8 equal $1.6 \mathrm{~m}$, and that between AR6 and AR8 equal $2.85 \mathrm{~m}$.

The global circulation is varied by varying the gas flow in the AR and CR. The time period modeled in Table 3 primarily depended on circulation: at high circulation, only a short time span needed to be modeled, and vice versa. $N$ denotes the number of CSTRs connected in series, being only a number generated during fitting the experimental data to the model, as is also the case for $\tau$ and $k$. Table 3 also includes a batch experiment performed by Markström et al. using ilmenite as oxygen carrier [27]. The results of the ilmenite experiment have been re-evaluated in order to make sure that the evaluation is identical to the method used in this study. 
Table 3. Summary of 24 batch tests, including a previous batch test performed with ilmenite as an oxygen carrier.

\begin{tabular}{|c|c|c|c|c|c|c|c|c|c|}
\hline $\begin{array}{c}\text { Batch } \\
\text { test ID }\end{array}$ & $\begin{array}{c}\overline{\dot{m}}_{\text {riser }} \\
\text { (kg/min) } \\
\text { AR7-8 }\end{array}$ & $\begin{array}{c}\overline{\dot{m}}_{\text {riser }} \\
\text { (kg/min) } \\
\text { AR6-8 }\end{array}$ & $\begin{array}{c}F_{\mathrm{AR}}\left(L_{\mathrm{n}} /\right. \\
\min )\end{array}$ & $\begin{array}{c}F_{\mathrm{CR}} \\
(\mathrm{kg} / \\
\mathrm{h})\end{array}$ & $\begin{array}{c}\text { Modeled } \\
\text { time (min) }\end{array}$ & $N(-)$ & $\begin{array}{c}\tau \\
(\min )\end{array}$ & $\begin{array}{l}m_{F R+} \\
(\mathrm{kg})\end{array}$ & $\begin{array}{l}\text { Model results, } \\
\overline{\dot{m}} \text { (kg/min) } \\
\text { [eq. (7)] }\end{array}$ \\
\hline 1 & 247 & 328 & 2024 & 5 & 9 & 9.3 & 6.3 & 132.8 & 21.0 \\
\hline 2 & 476 & 589 & 2530 & 5 & 6.5 & 9.2 & 4.4 & 155.2 & 35.4 \\
\hline 3 & 350 & 452 & 2277 & 5 & 6.5 & 12.4 & 4.9 & 141.2 & 28.8 \\
\hline 4 & 503 & 668 & 2530 & 7 & 5.5 & 8.5 & 3.8 & 141.6 & 36.9 \\
\hline 5 & 529 & 687 & 2530 & 8 & 6 & 9.8 & 4.0 & 137.0 & 34.3 \\
\hline 6 & 536 & 726 & 2530 & 10 & 5.5 & 9.9 & 3.6 & 129.2 & 35.5 \\
\hline 7 & 597 & 859 & 2530 & 10 & 5 & 12.5 & 3.5 & 142.7 & 40.8 \\
\hline 8 & 586 & 835 & 2530 & 10 & 5.5 & 10.6 & 3.6 & 138.9 & 38.4 \\
\hline 9 & 605 & 802 & 2530 & 10 & 5 & 9.9 & 3.4 & 145.3 & 42.2 \\
\hline 10 & 336 & 544 & 2023 & 10 & 6 & 9.9 & 4.1 & 115.2 & 28.3 \\
\hline 11 & 259 & 487 & 1822 & 10 & 7 & 13.4 & 4.9 & 107.2 & 21.7 \\
\hline 12 & 197 & 284 & 1822 & 5 & 9 & 10.8 & 6.5 & 112.7 & 17.5 \\
\hline 13 & 256 & 341 & 2024 & 5 & 8 & 11.7 & 5.9 & 125.4 & 21.3 \\
\hline 14 & 354 & 599 & 2025 & 10 & 6 & 11.8 & 4.4 & 112.2 & 25.7 \\
\hline 15 & 333 & 523 & 2024 & 10 & 6 & 11.6 & 4.4 & 110.3 & 25.1 \\
\hline 16 & 244 & 283 & 2024 & 5 & 8 & 8.3 & 5.8 & 115.5 & 19.9 \\
\hline 17 & 181 & 211 & 1822 & 5 & 10 & 7.0 & 6.7 & 104.0 & 15.5 \\
\hline 18 & 138 & 158 & 1680 & 5 & 12 & 7.8 & 7.4 & 99.4 & 13.5 \\
\hline 19 & 418 & 429 & 2530 & 5 & 6.5 & 8.3 & 4.9 & 132.1 & 27.2 \\
\hline 20 & 304 & 431 & 2024 & 5 & 6.5 & 8.3 & 4.9 & 126.5 & 25.9 \\
\hline 21 & 162 & 218 & 1680 & 5 & 8.5 & 8.2 & 7.1 & 108.4 & 15.3 \\
\hline 22 & 160 & 215 & 1680 & 5 & 10 & 5.8 & 6.5 & 109.0 & 16.8 \\
\hline 23 & 270 & 341 & 2025 & 5 & 9 & 8.4 & 6.1 & 132.8 & 21.9 \\
\hline 24 & 438 & 490 & 2530 & 5 & 7.5 & 11.6 & 4.9 & 152.6 & 31.1 \\
\hline Ilmenite & 271 & 339 & 1680 & 5 & 10 & 9.9 & 6.2 & 125.3 & 20.2 \\
\hline
\end{tabular}

Figure 6 shows the model results (shown in the far right column in Table 3) plotted versus the pressure drop in the AR riser, with fitting performed using linear regression and the fit quality evaluated based on the coefficient of determination. The coefficient of determination, $r^{2}$, is a measure of how well the fitted line approximates the experimental data, with a value of unity corresponding to a perfect fit. In 
the present experiments, the coefficient of determination equaled 0.97 for AR7-8 (i.e., the shorter AR riser section (Figure 6A)) and 0.91 for AR6-8 (Figure 6B). Hence, calculating $\dot{m}_{\text {riser }}$ using AR7-8 increases the predictability or expected accuracy of the model, showing that circulation can be calculated as:

$$
\dot{m}=6.6+0.057 \dot{m}_{\text {riser }}(\mathrm{kg} / \mathrm{min})
$$

This model can be used in the investigated interval, but is not applicable for lower circulation values, since the relationship between the actual circulation and the riser pressure drop is difficult to investigate in this case. Although no solids circulation is expected for a riser pressure drop of zero, one cannot exclude the possibility that small riser pressure drops can occur in the absence of circulation at certain operating conditions, e.g., if particles are thrown up into the top levels of the riser but do not reach the cyclone inlet. In practice, however, the difficulty of predicting low-level circulation is not a problem, since operation under these conditions would lead to an insufficient supply of oxygen to the fuel reactor and hence cannot be employed in a CLC process.

Notably, the ilmenite experiment (see Table 3) fitted the Sinaus data presented here very well. This behavior was expected, since these oxygen carrier materials are very similar in terms of density, particle size, and sphericity. Moreover, it should be stressed that the correlation described by eq. (8) is valid only for the investigated reactor system. However, the results demonstrate the viability of this model, which is generally applicable and can be used to obtain the solids circulation in essentially any dual fluidized bed system.

Furthermore, the correlation between the pressure drop over the bottom part of two loop seals, LS3 and LS4, and the solids circulation was not as strong as that observed for the riser pressure drop (Figure 7). In Figure 7B, five model data points were removed due to the blocking of the LS4B pressure tap. The coefficients of determination equaled 0.82 and 0.68 for LS3 and LS4, respectively. In LS3, the pressure difference between pressure taps B and C was negative at low circulations, which could be caused by the fact that the taps were placed at slightly different heights above the distributor or by a slight inclination of the loop seal as a result of operation. It should also be noted that the difference in $\Delta P$ for highest and lowest circulation values equaled $0.35 \mathrm{kPa}$ for LS3 and $0.53 \mathrm{kPa}$ for LS4. Hence, LS4 experienced a higher pressure difference (B-C) at equal circulation, which could be explained by small differences in loop seal geometry or tap placement.

Finally, the importance of having a good real-time estimate of the solids circulation during operation should be made clear. Such an estimate cannot be provided by pressure drop measurements in loop seals, which requires longer time-averaging periods than estimates based on AR riser pressure drops. Consequently, the choice of internal AR riser mass flow for estimating global circulation is obvious from the viewpoints of correlation with model data and operational considerations.

\section{Conclusions}

Herein, the solids circulation in a $100-\mathrm{kW}$ chemical looping combustor was investigated by adding fuel batches and modeling the fuel reactor and adjacent vessels as sequentially connected CSTRs. Analysis of the gas exiting the air reactor allowed the residence time of oxygen carrier particles to be determined for particular batch experiments. After performing a number of such experiments, the solids circulation could be correlated with other experimental data. The results of 24 batch experiments using Sinaus as an oxygen carrier revealed an excellent correlation between the flow of particles in the AR riser and the actual circulation obtained in the above experiments. The relationship between global circulation, $\dot{m}$, and AR riser mass flow, $\dot{m}_{r i s e r}$, was found to be linear: 
$\dot{m}=6.6+0.057 \dot{m}_{\text {riser }}$, being valid only for the investigated reactor system. Although the above relationship could not be directly applied to a reactor system of different geometry, the model used to determine the solids circulation could be used to derive a similar correlation for any other dual fluidized bed system.

Furthermore, the relationship between the pressure drop over the bottom part of two loop seals and the solids circulation was investigated, revealing a correlation that was not as strong as that between circulation and the riser pressure drop.

\section{Acknowledgements}

The research leading to these results received funding from (a) the European Research Council under the Seventh Framework Programme ERC Grant Agreement no 291235 of the European Union. Ulf Stenman is gratefully acknowledged for valuable technical assistance. 


\section{Figure Captions}

Figure 1. The Chalmers $100 \mathrm{~kW}$ CLC unit. Left: 2D sketch with pressure tap positions and names. Notations in bold indicate names of reactor vessels. Right: 3D image of system.

Figure 2. Mass fractions of fresh and used (from AR and FR) oxygen carrier particles.

Figure 3. Sinaus particles sieved to size interval 125-180 $\mu \mathrm{m}$. Left: particles used during operation, from AR. Right: fresh particles.

Figure 4. Solids inventory in different parts of the reactor system. "FR+" = FR+CS+CR+LS2+LS3+LS4.

Figure 5. Measurement data from four batch tests with fitted functions $f(t)=\left(\mathrm{O}_{2}\right)_{A R}(t)$, eq. (6).

Figure 6. All 24 batch experiments plotted as model results versus mass flow in AR riser. A: $\dot{m}_{\text {riser }}$ obtained by using pressure drop AR7-8 (1.6 m); B: same kind of plot using AR6-8 (2.85 m).

Figure 7. All 24 batch experiments plotted versus the pressure drop over the bottom part of loop seals 3 and 4 (LS3B-C and LS4B-C, cf. Figure 1).

\section{References}

1. Ishida, M. and H.G. Jin, Greenhouse gas control by a novel combustion: No energy penalty and no CO2 separation equipment. Greenhouse Gas Control Technologies, 1999: p. 627-632.

2. Lewis, W.K. and E.R. Gilliland, Productions of pure carbon dioxide. US Patent No. 2,665,972. 1954.

3. Lyngfelt, A. and C. Linderholm, Chemical-Looping Combustion of Solid Fuels - status and recent progress. 13th International Conference on Greenhouse Gas Control Technologies, GHGT-13, 14-18 November 2016, Lausanne, Switzerland, 2016.

4. Lyngfelt, A., Oxygen Carriers for Chemical-Looping Combustion, Chapter 11, in "Calcium and chemical looping technology for power generation and carbon dioxide (CO2) capture". Eds Fennell, P., and Anthony, E.J., Woodhead Publishing, 2015: p. 221-254

5. Wang, P., N. Means, D. Shekhawat, D. Berry, and M. Massoudi, Chemical-Looping Combustion and Gasification of Coals and Oxygen Carrier Development: A Brief Review. Energies, 2015. 8(10): p. 10605-10635.

6. Bayham, S.C., H.R. Kim, D.W. Wang, A. Tong, L. Zeng, O. McGiveron, M.V. Kathe, E. Chung, W. Wang, A.N. Wang, A. Majumder, and L.S. Fan, Iron-Based Coal Direct Chemical Looping Combustion Process: 200-h Continuous Operation of a 25-kW(th) Subpilot Unit. Energy \& Fuels, 2013. 27(3): p. 1347-1356.

7. Sozinho, T., W. Pelletant, H. Stainton, F. Guillou, and T. Gauthier, Main results of the $10 \mathrm{kWth}$ pilot plant operation. 2nd International Conference on Chemical Looping, 26-28 September 2012, Darmstadt, Germany, 2012.

8. Thon, A., M. Kramp, E.-U. Hartge, S. Heinrich, and J. Werther, Operational experience with a system of coupled fluidized beds for chemical looping combustion of solid fuels using ilmenite as oxygen carrier. Applied Energy, 2014. 118: p. 309-317.

9. Markström, P., C. Linderholm, and A. Lyngfelt, Chemical-looping combustion of solid fuels Design and operation of a $100 \mathrm{~kW}$ unit with bituminous coal. International Journal of Greenhouse Gas Control, 2013. 15: p. 150-162. 
10. Adánez, J., A. Abad, R. Perez-Vega, L. de Diego, F. García-Labiano, and P. Gayán, Design and Operation of a Coal-fired $50 \mathrm{kWth}$ Chemical Looping Combustor. Energy Procedia, 2014. 63(2014): p. 63-72.

11. Xiao, R., L.Y. Chen, C. Saha, S. Zhang, and S. Bhattacharya, Pressurized chemical-looping combustion of coal using an iron ore as oxygen carrier in a pilot-scale unit. International Journal of Greenhouse Gas Control, 2012. 10: p. 363-373.

12. Shen, L.H., J.H. Wu, J. Xiao, Q.L. Song, and R. Xiao, Chemical-Looping Combustion of Biomass in a $10 \mathrm{~kW}$ (th) Reactor with Iron Oxide As an Oxygen Carrier. Energy \& Fuels, 2009. 23: p. 2498-2505.

13. Tong, A., S. Bayham, M.V. Kathe, L. Zeng, S.W. Luo, and L.S. Fan, Iron-based syngas chemical looping process and coal-direct chemical looping process development at Ohio State University. Applied Energy, 2014. 113: p. 1836-1845.

14. Mendiara, T., M.T. Izquierdo, A. Abad, L.F. de Diego, F. García-Labiano, P. Gayán, and J. Adánez, Performance of a Fe-based residue using different coals in a 500 Wth CLC unit. 2nd International Conference on Chemical Looping, 26-28 September 2012, Darmstadt, Germany, 2012.

15. Ohlemüller, P., J.-P. Busch, J. Ströhle, and B. Epple, Autothermal operation of a $1 \mathrm{MWth}$ chemical looping plant. 22nd International Conference on Chemical Looping, June 14-17. 2015, Turku, Finland, 2015.

16. Ströhle, J., M. Orth, and B. Epple, Design and operation of a $1 \mathrm{MWth}$ chemical looping plant. Applied Energy, 2014. 113: p. 1490-1495.

17. Linderholm, C., P. Knutsson, M. Schmitz, P. Markström, and A. Lyngfelt, Material balances of carbon, sulfur, nitrogen and ilmenite in a $100 \mathrm{~kW} \mathrm{CLC} \mathrm{reactor} \mathrm{system.} \mathrm{International} \mathrm{Journal} \mathrm{of}$ Greenhouse Gas Control, 2014. 27(2014): p. 188-202.

18. Sundqvist, S., M. Arjmand, T. Mattisson, M. Rydén, and A. Lyngfelt, Screening of different manganese ores for chemical-looping combustion (CLC) and chemical-looping with oxygen uncoupling (CLOU). International Journal of Greenhouse Gas Control, 2015. 43: p. 179-188.

19. Arjmand, M., H. Leion, A. Lyngfelt, and T. Mattisson, Use of manganese ore in chemicallooping combustion (CLC)-Effect on steam gasification. International Journal of Greenhouse Gas Control, 2012. 8: p. 56-60.

20. Linderholm, C., A. Lyngfelt, A. Cuadrat, and E. Jerndal, Chemical-looping combustion of solid fuels - Operation in a $10 \mathrm{~kW}$ unit with two fuels, above-bed and in-bed fuel feed and two oxygen carriers, manganese ore and ilmenite. Fuel, 2012. 102: p. 808-822.

21. Lyngfelt, A. and B. Leckner, A 1000 MWth Boiler for Chemical-Looping Combustion of Solid Fuels - Discussion of Design and Costs. Applied Energy Technology, 2015. 157(2015): p. 475487.

22. Bhusarapu, S., P. Fongarland, M. Al-Dahhan, and M.P. Dudukovic, Measurement of overall solids mass flux in a gas-solid circulating fluidized bed. Powder Technology, 2004: p. 158-171.

23. Abad, A., I. Adanez-Rubio, P. Gayan, F. Garcia-Labiano, L.F. de Diego, and J. Adanez, Demonstration of chemical-looping with oxygen uncoupling (CLOU) process in a $1.5 \mathrm{~kW}(\mathrm{th})$ continuously operating unit using a Cu-based oxygen-carrier. International Journal of Greenhouse Gas Control, 2012. 6: p. 189-200.

24. Dietrich, F., G. Tondl, D. Wöss, T. Pröll, and H. Hofbauer, Comparison of Four Different Methods for Measuring the Solids Circulation Rate in Circulating Fluidized Beds" in "The 14th International Conference on Fluidization - From Fundamentals to Products", J.A.M. Kuipers, Eindhoven University of Technology R.F. Mudde, Delft University of Technology J.R. van Ommen, Delft University of Technology N.G. Deen, Eindhoven University of Technology Eds, ECI Symposium Series, (2013).

25. Linderholm, C., T. Mattisson, and A. Lyngfelt, Long-term integrity testing of spray-dried particles in a 10-kW chemical-looping combustor using natural gas as fuel. Fuel, 2009. 88(11): p. 2083-2096. 
26. Kolbitsch, P., Chemical looping combustion for 100\% carbon capture - Design, operation and modeling of a $120 \mathrm{~kW}$ pilot rig. Ph. D thesis, Technical University of Vienna, 2009.

27. Markstrom, P., C. Linderholm, and A. Lyngfelt, Operation of a $100 \mathrm{~kW}$ chemical-looping combustor with Mexican petroleum coke and Cerrejon coal. Applied Energy, 2014. 113: p. 1830-1835.

28. Linderholm, C., M. Schmitz, M. Biermann, M. Hanning, and A. Lyngfelt, Chemical-looping combustion of solid fuel in a $100 \mathrm{~kW}$ unit using sintered manganese ore as oxygen carrier. Submitted for publication, 2017.

29. Linderholm, C., A. Lyngfelt, M. Rydén, and M. Schmitz, Chemical-looping combustion of biomass in a $100 \mathrm{~kW}$ pilot. EUBCE 2017, 12-15 June, Stockholm, Sweden, 2017.

30. Johansson, E., A. Lyngfelt, T. Mattisson, and F. Johnsson, A circulating fluidized bed combustor system with inherent $\mathrm{CO} 2$ separation - application of chemical looping combustion. 7th Int. Conf. on Circulating Fluidized Beds, Niagara Falls, Ontario, May 5-7, 2002, 717-724.

31. Markström, P., N. Berguerand, and A. Lyngfelt, The application of a multistage-bed model for residence-time analysis in chemical-looping combustion of solid fuel. Chemical Engineering Science, 2010. 65(18): p. 5055-5066.

32. Linderholm, C., M. Schmitz, P. Knutsson, and A. Lyngfelt, Chemical-looping combustion in a 100-kW unit using a mixture of ilmenite and manganese ore as oxygen carrier. Fuel, 2016. 166: p. 533-542. 


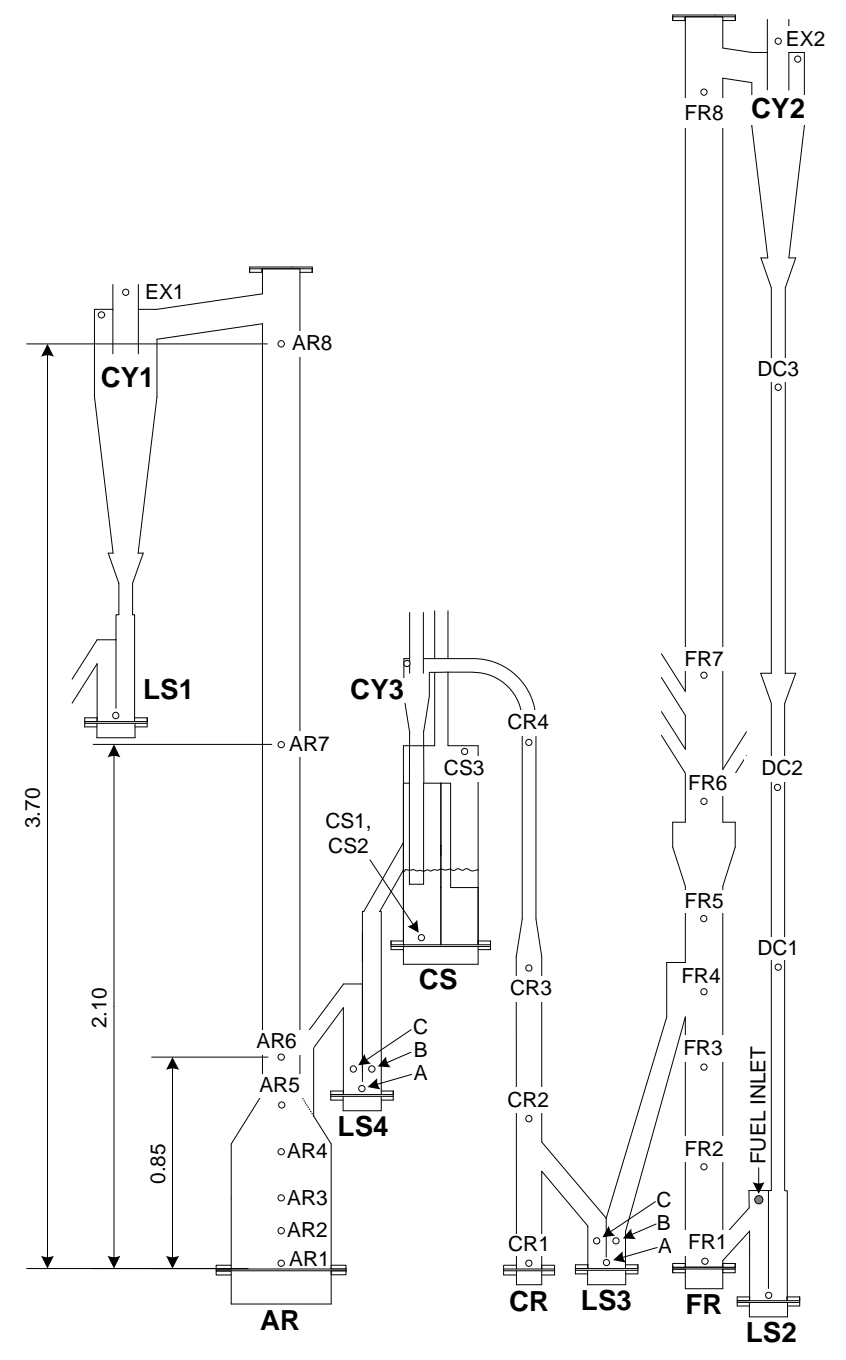




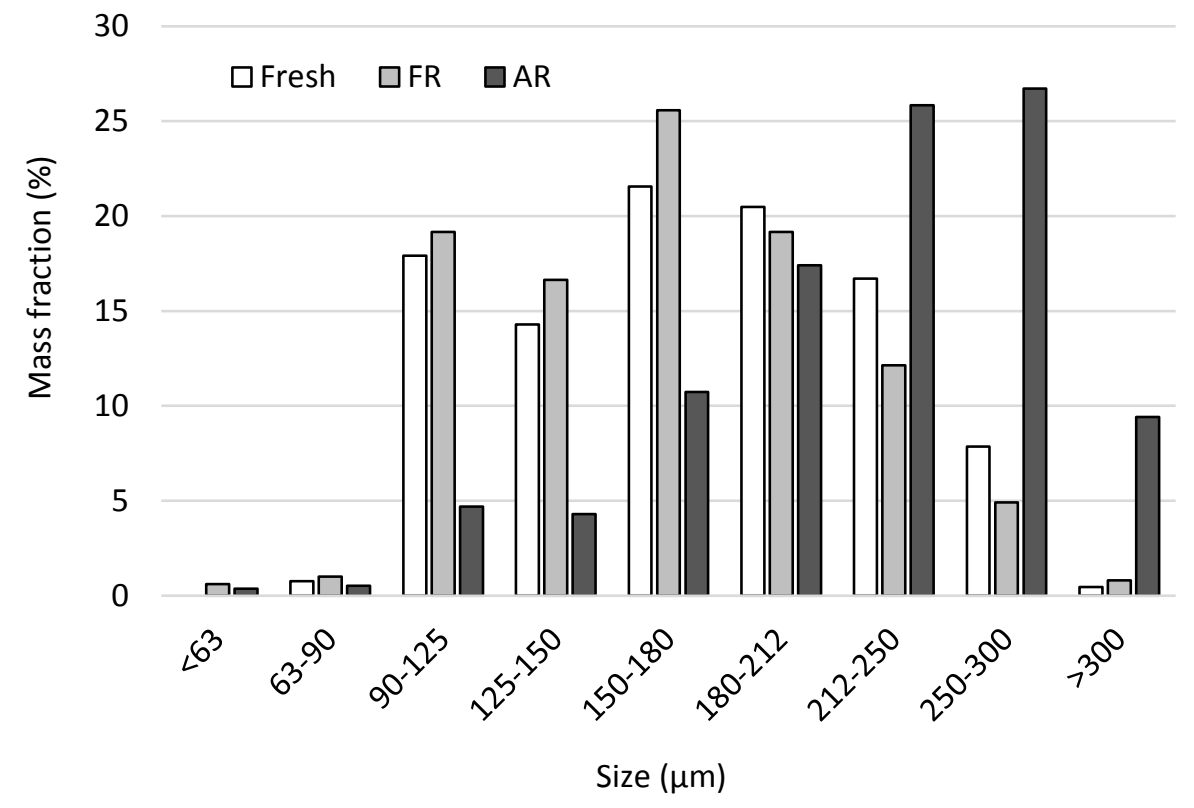




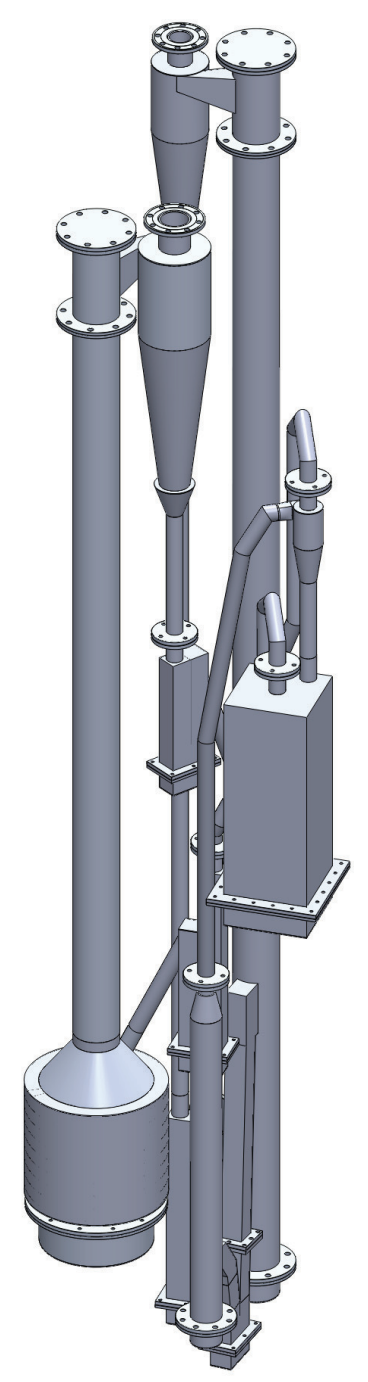



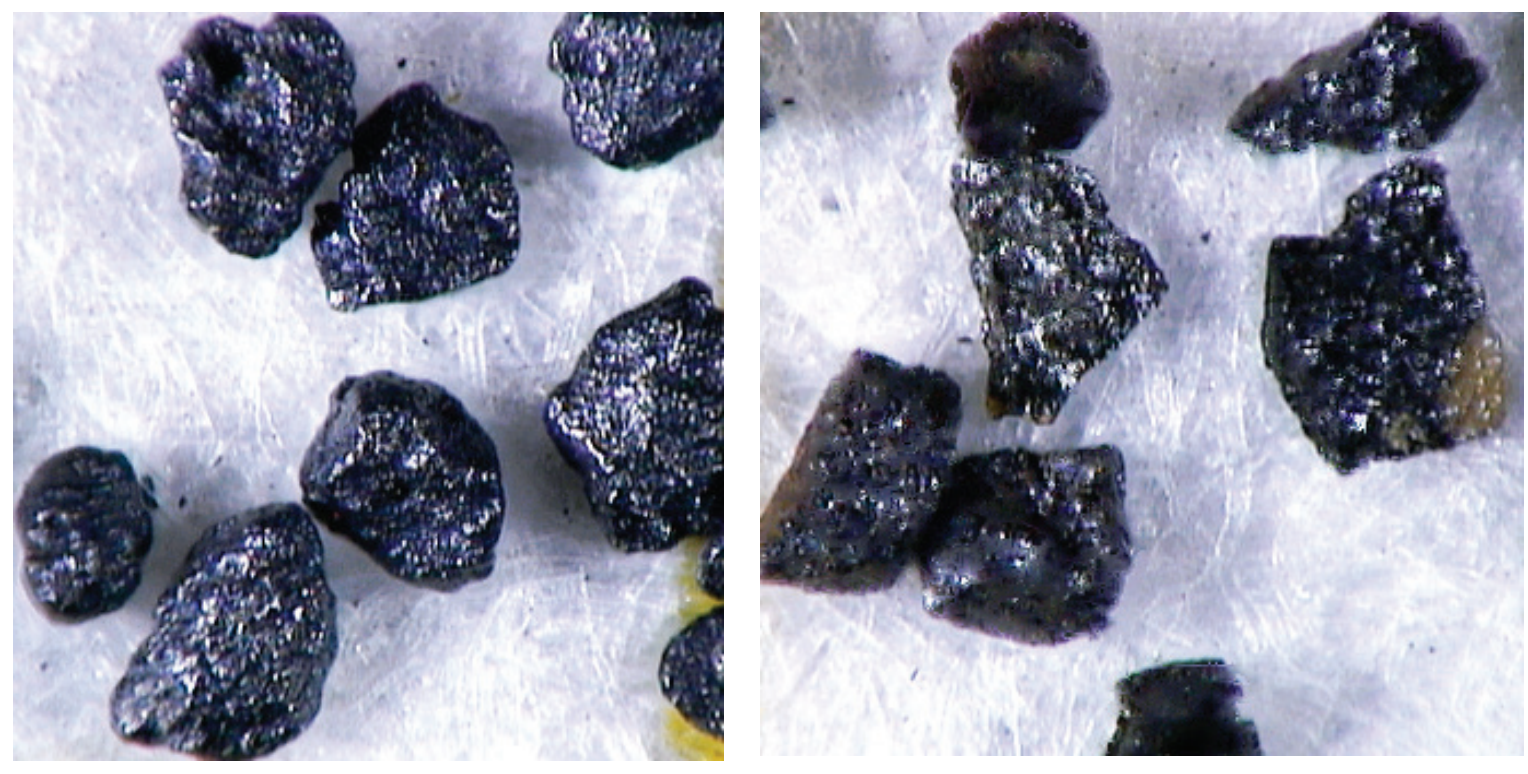


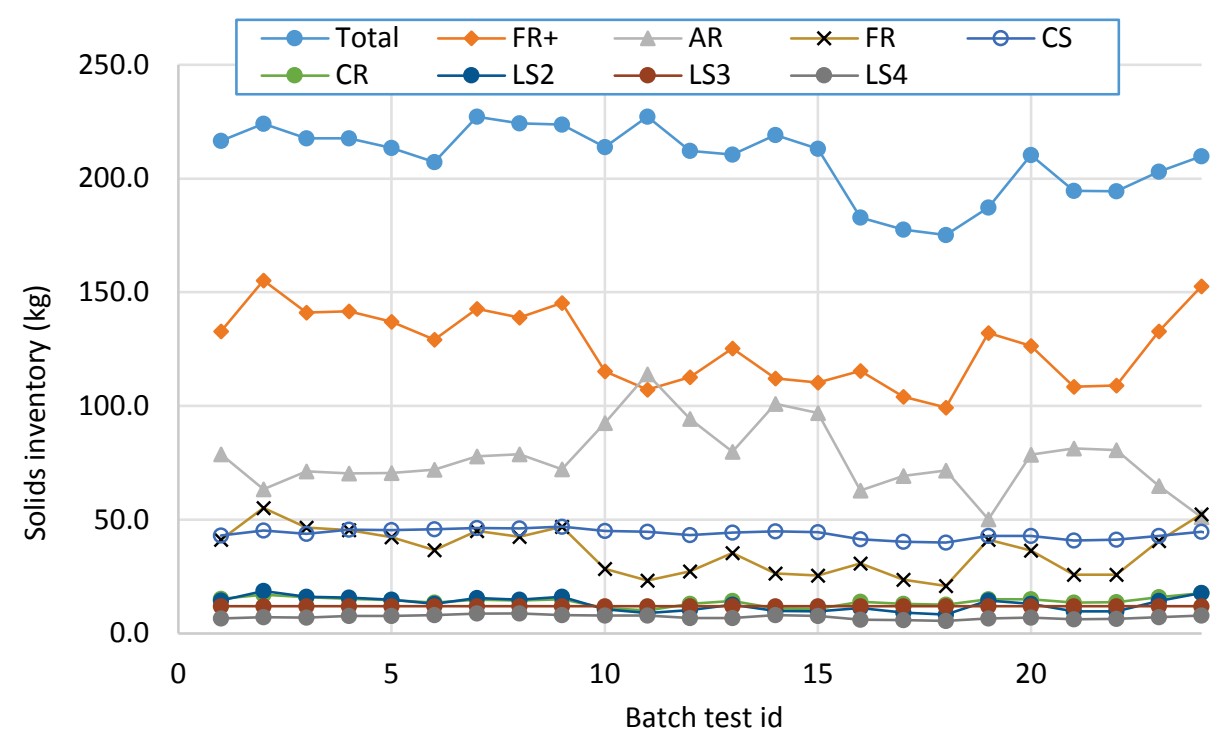



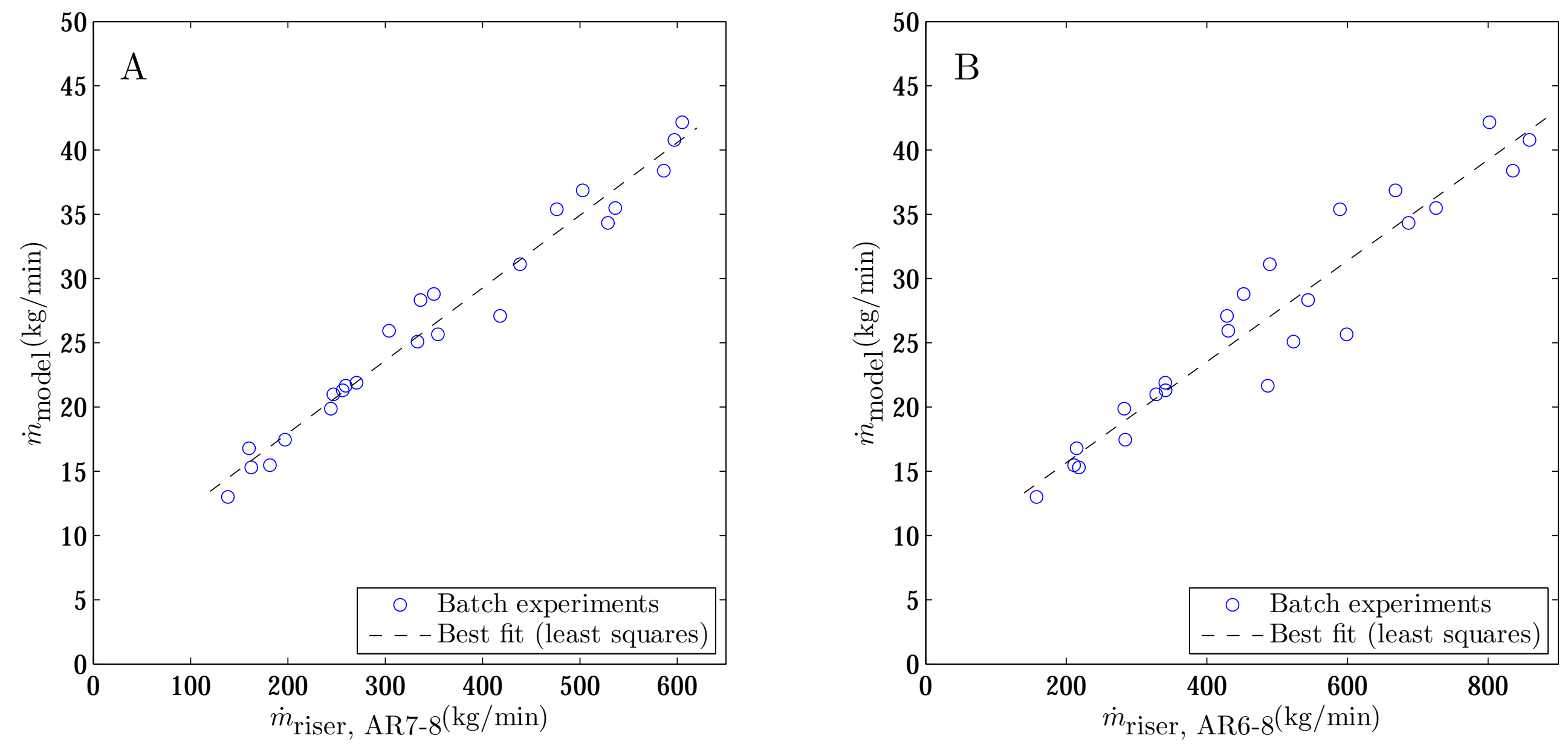

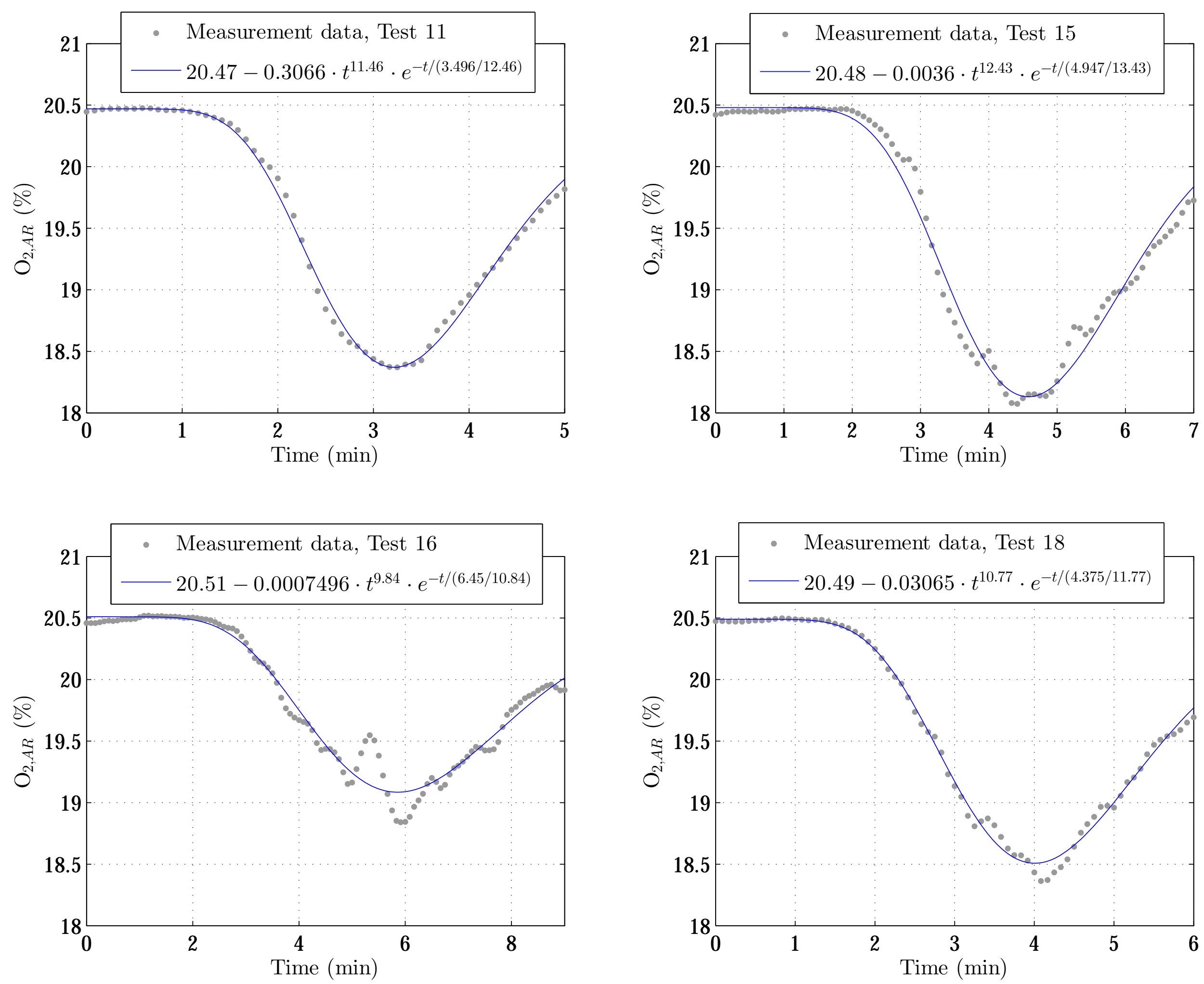

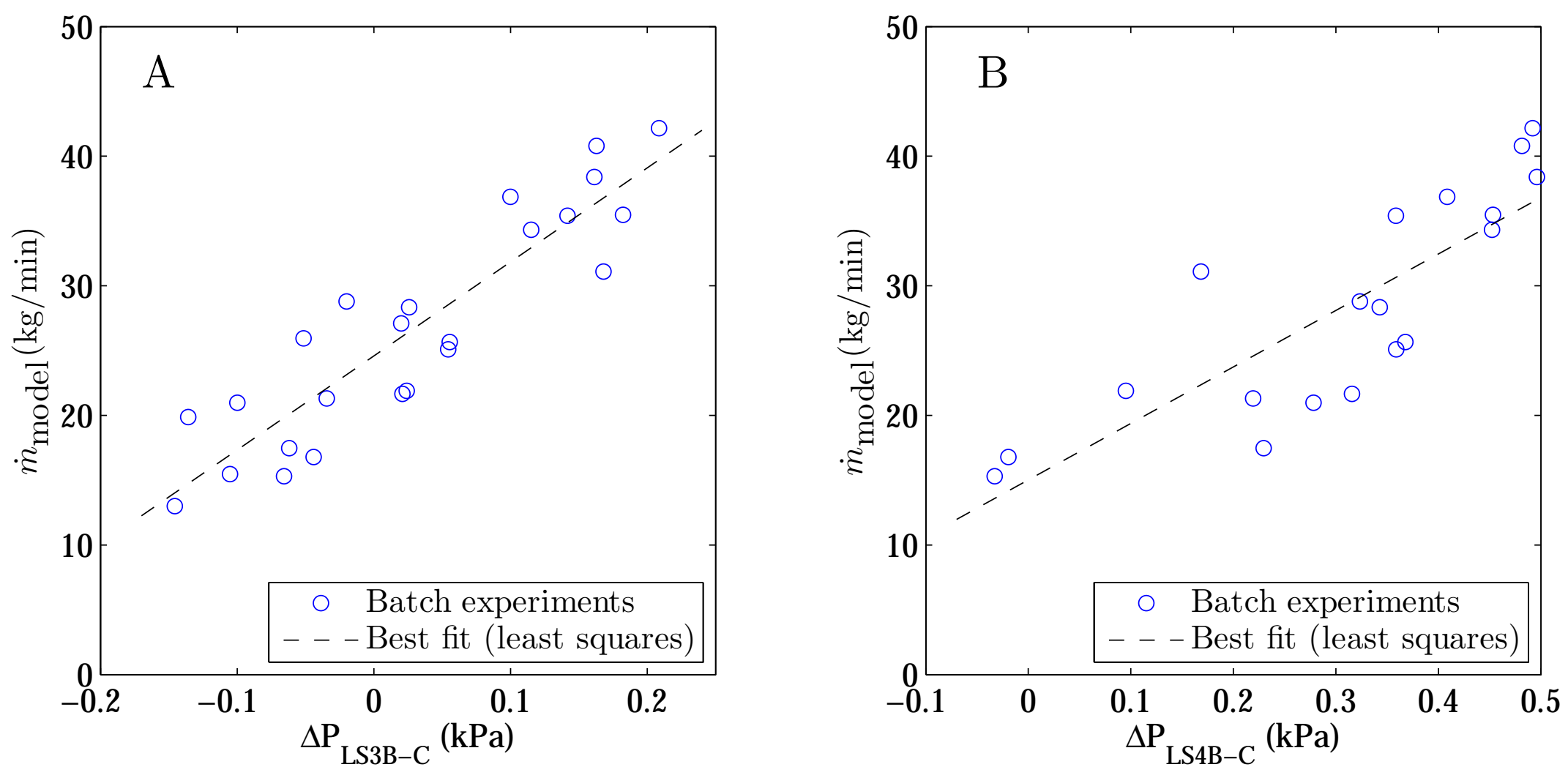